\title{
Mutations in the HML E silencer of Saccharomyces cerevisiae yield metastable inheritance of transcriptional repression
}

\author{
Deborah J. Mahoney, ${ }^{1}$ Rüdiger Marquardt, ${ }^{2}$ Gan-Ju Shei, Alan B. Rose, ${ }^{3}$ and James R. Broach \\ Department of Biology, Princeton University, Princeton, New Jersey 08544 USA
}

\begin{abstract}
Mating-type genes resident in the silent cassette $H M L$ at the left arm of chromosome III are repressed by the action of four SIR gene products, mediated independently through two cis-acting sites, termed the E and I silencers. We have found that in the absence of the I silencer, deletion of any one of three distinct elements within $\mathrm{E}$ yields partial derepression of the mating-type genes resident at $H M L$, whereas deletion of any two yields full derepression. These elements correspond to a binding site for the abundant DNA-binding protein RAP1, an autonomous replicating sequence (ARS), and an as yet undistinguished region. From detailed deletion analysis of the E site we conclude that the ARS element contributes to silencer function in a capacity distinct from its role as an initiator of DNA replication. In addition, we find that strains deleted for any one of these elements comprise two genetically identical but phenotypically distinct types of cells: Those with $H M L$ apparently fully derepressed, and those with $H M L$ apparently completely repressed. These results reinforce the notion that epigenetic inheritance is an intrinsic characteristic of silencer action.
\end{abstract}

[Key Words: $H M L$ silencer; S. cerevisiae; mating-type genes]

Received December 3, 1990; revised version accepted January 24, 1991.

The transcriptional state of a gene in a cell is occasionally as dependent on the history of the cells from which it derived as it is on its genetic composition. Several instances have been noted in which bacterial cells with identical genotypes exhibit two quite distinct quasi-stable phenotypes, due to epigenetic inheritance of the transcription state of a particular gene /Cohn and Horibata 1959; Eisen et al. 1970). In eukaryotic cells, several loci have been identified that are expressed differently when maternally inherited than when paternally inherited. For instance, Swain et al. (1987) found that a transgenic c$m y c$ gene was expressed in those mice that inherited the gene from their father but was not expressed in mice that inherited it from their mother. Expression of the transgene in these experiments correlated with the methylation state of the DNA spanning the locus. Other cases of genetic imprinting have been identified, although correlation with the methylation state of DNA is not absolute (Cedar 1988; Holliday 1988).

The silent mating-type genes of Saccharomyces cerevisiae may provide another example of genetic imprinting, although the mechanism of this epigenetic event is

Present addresses: ${ }^{1}$ Whitehead Institute, Cambridge Massachusetts 02142 USA; ${ }^{2}$ Hoechst Aktiengesellschaft, 6230 Frankfort am Main 80, Germany; ${ }^{3}$ Boyce Thompson Institute, Cornell University, Ithaca, New York 14853 USA. clearly distinct from those cited above. In this organism cell type is determined by regulatory proteins encoded by genes present at a locus, $M A T$, located on chromosome III (Herskowitz and Oshima 1981; Nasmyth 1982; Haber 1983; Sprague et al. 1983; Klar et al. 1984). These same genes are also found at either end of chromosome III, at loci designated $H M L$ and $H M R$ (Nasmyth and Tatchell 1980; Strathern et al. 1980; Astell et al. 1981). However, whereas the genes resident at $M A T$ are expressed to establish and maintain cell type, the identical genes at $H M L$ and $H M R$ are transcriptionally inactive and do not contribute to the phenotype of the cell (Klar et al. 1981; Nasmyth et al. 1981). Normally, the only means by which the genes resident at these silent cassettes can be activated is by transposition of the genes to MAT (Hicks et al. 1979; Klar and Fogel 1979; Kushner et al. 1979; Klar 1980; Klar et al. 1982).

The mechanism by which $H M L$ and $H M R$ are rendered transcriptionally silent is unknown, although many of the components required for repression of these loci have been identified. Three proteins, encoded by the genes SIR2, SIR3, and SIR4, are required for transcriptional repression (Haber and George 1979; Klar et al. 1979; Rine et al. 1979; Rine and Herskowitz 1987). Inactivation of any one of these genes yields phenotypic expression of the silent loci, with transcription of the mating-type genes at both $H M L$ and $H M R$ in a $\mathrm{Sir}^{-}$background 
achieving a level equivalent to that seen for the genes at MAT (Ivy et al. 1986; Rine and Herskowitz 1987). In addition, specific mutant alleles in HHF1, one of the structural genes for histone $\mathrm{H} 4$, yield full expression of the silent cassettes (Kayne et al. 1988).

Inactivation of a fifth gene, SIR 1 , results in an unusual pattern of expression of the silent cassettes and reveals an epigenetic mode of inheritance of their transcriptional state. Complete inactivation of SIR1 causes partial expression of the silent cassettes, as determined by assays that evaluate expression within a population, such as measurement of $H M L$-specific mRNA levels or colony mating behavior (Ivy et al. 1986; Rine and Herskowitz 1987). However, by examining the mating potential of individual sir1 cells, Pillus and Rine (1989) concluded that partial expression of $H M L$ evident at a population-wide basis is a consequence of the persistence of two distinct types of cells in a culture. One cell type behaved as if cells were fully repressed for $H M L$ expression, and one type behaved as if cells were fully derepressed. In addition, Pillus and Rine found that $>99 \%$ of daughter cells assume the repression state of their parent. Thus, phenotypic repression of the silent loci in a sir1 strain exhibits epigenetic inheritance.

In this report we describe similar results obtained with cells carrying mutations within the cis-acting silencer domains that mediate $S I R$-dependent repression of the silent loci. SIR repression of the silent cassettes requires the integrity of specific cis-acting sites, termed silencers, located adjacent to the loci (Abraham et al. 1984; Feldman et al. 1984; Brand et al. 1985). At HMR a single site, designated $\mathrm{E}$, acts in an orientation-independent manner to repress expression of the mating-type genes or other polymerase II or polymerase III transcription units inserted at the locus (Brand et al. 1985; Schnell and Rine 1986). HMR E consists solely of three elements: binding sites for two abundant DNA-binding proteins, RAP1 and $\mathrm{ABF} 1$, as well as a consensus autonomously replicating sequence (ARS) core element (Broach et al. 1983b; Shore and Nasmyth 1987; Shore et al. 1987; Buchman et al. 1988; F. McNally, A. Axelrod, and J.D. Rine, pers. comm.). Elimination of any one of these elements does not abolish silencer function, whereas elimination of any two of the elements yields complete derepression of the locus (Brand et al. 1987; Kimmerly et al. 1988). In contrast, repression of $H M L$ is mediated by two functionally equivalent silencers, designated $\mathrm{E}$ and I, either of which is sufficient for complete repression (Mahoney and Broach 1989). HML E spans two identifiable elements: a binding site for RAP1 and an ARS core consensus element (Feldman et al. 1984; Buchman et al. 1988). However, the functional significance of the presence of these elements has not been established.

To address the mechanism of mating-type silencing, we undertook a fine-structure genetic analysis of the $H M L E$ silencer. The results of this analysis, presented in this report, indicate that partial inactivation of the $H M L$ E silencer also yields mixed populations of two cells types, whose slow rate of interconversion fortifies the hypothesis of an epigenetic component of mating-type repression. These results help define the nature of a silencer and the process of transcriptional silencing.

\section{Results}

\section{HML consists of three domains}

Previous deletion analysis of the $H M L$ E site revealed that sequences essential for $\mathrm{E}$ site silencer activity lay within a 150-bp region $200 \mathrm{bp}$ to the telomere side of HML (Feldman et al. 1984; Mahoney and Broach 1989). We constructed a number of deletion/substitution mutations within and around this region in vitro and then used transformation to substitute these mutations for the wild-type $H M L \mathrm{E}$ site in our parental MATa strain. The various deletion/substitution alleles examined in this study are diagramed in Figure 1 . To evaluate the effects of mutations in $\mathrm{E}$ on silencer function we had to render repression of the $H M L \alpha$ cassette exclusively dependent on the E silencer. This was accomplished by using as our recipient strain one in which the I silencer had been deleted (Mahoney and Broach 1989). In this manner, expression of $\alpha$-mating information resident at $H M L$ could serve as a direct metric of $\mathrm{E}$ site silencing activity.

$H M L$ expression in strains harboring the mutant $\mathrm{E}$ alleles was measured initially by quantitative mating assays. The $H M L$ locus we examined carried $\alpha$-mating-type information. If the $H M L$ locus was repressed, then only a-mating information from the MATa locus was expressed and the cell mated as an a. If repression of $H M L$ was relieved, then both a-mating information and $\alpha$-mating information were expressed and then cell assumed a sterile a/ $\alpha$ phenotype (Dranginis 1986 ; Herskowitz 1989|. Thus, the degree to which the a-mating competence of the test strain was diminished reflected the extent to which the $H M L$ locus was derepressed.

The effects of various deletion/substitution mutations at $H M L \mathrm{E}$ on $H M L$ expression, as measured by quantitative-mating assays, are presented in Figure 1. Two elements within the $\mathrm{E}$ region had been identified previously by sequence comparisons and binding studies: an ARS consensus element and a binding site for the abundant DNA-binding protein RAP1. We found that mutations confined to either of these two elements caused a partial reduction in a mating, as evidenced by the reduced mating competence of strains DMY116 and DMY34 as compared to that of DMY1. Mutations that impinged on both of these elements caused a severe depression in a mating (e.g., strain DMY26). In addition, these studies highlighted a third region, designated $\mathrm{D}$ in Figure 1 and lying to the right of the ARS consensus element. Elimination of $D$ yielded a small but reproducible reduction in a mating, whereas deletion of both the ARS element and D yielded a much more substantial reduction in mating than did deletion of the ARS element alone (cf. the mating of strains DMY13 and DMY34). Thus, these results suggested that $H M L \mathrm{E}$ is composed of three elements: a RAP1-binding site, an ARS element, and a domain of unidentified function. Elimination of any one of these 


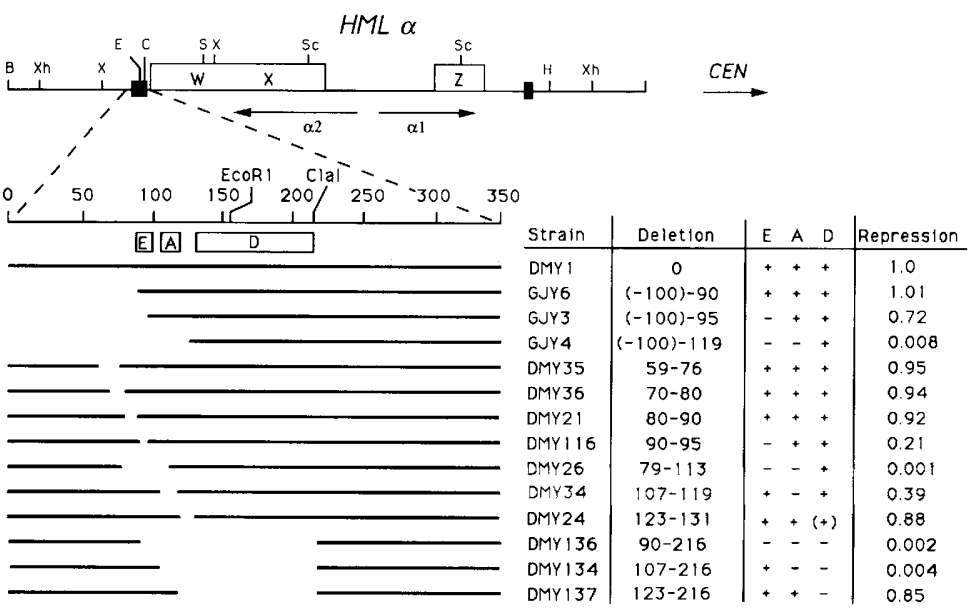

Figure 1. Mutant alleles of the $H M L$ E site. (Top) Diagram of the $H M L \alpha$ locus, indicating the positions of various restriction sites, the location of sequences of shared identity with the MAT locus (boxed segments), the positions and orientations of the two mating-type genes encoded at the locus, and the locations of the $\mathrm{E}$ and I silencer (solid boxes). Restriction site abbreviations: (B) BamHI; (C) ClaI; (E) EcoRI; (H) HindIII; (S) SpeI; (Sc) ScaI; (X) XbaI; (Xh) XhoI. The expanded E silencer region shows the locations of the RAPl-binding site [(E) position 90-100], the ARS consensus element [(A) position 107-117], a larger segment of currently unassigned function (D), and the EcoRI and ClaI restriction sites. The numbering system is as defined in Feldman et al. (1984); the $\mathrm{W}$ region of $H M L$ begins at position 359. Heavy lines below the diagram of $H M L \mathrm{E}$ indicate the sequences that remain in the deletion alleles present in the corresponding strains listed at right.

The deleted section is replaced by the octanucleotide linker CAGATCTG in each allele. To the right of the strain designation is indicated the mating efficiency of the strain containing the deletion allele, which reflects the degree of repression of the $H M L \alpha$ locus present in the strain. Mating efficiency was determined by quantitative-mating assays performed as described in Materials and methods, using DC17 $\alpha$ as tester strain. Results are expressed as percent mating-competent cells relative to strain DMY1. In this assay, $\sim 85 \%$ of the DMY1 cells mate to yield diploids.

components yielded partial expression of $H M L$, whereas elimination of two of the elements completely abolished silencer function.

Expression of $H M L$ in strains carrying the various deletion alleles could also be evaluated by determining the level of $\alpha$-specific mRNA. Total RNA from the indicated strains was hybridized with excess labeled RNA species specific for the MAT 2 transcript and the MATa1 transcript. MATa1 mRNA levels reflected expression from the MATa locus in the test strains and served as internal control. MAT 22 mRNA levels reflected the degree of expression of the $H M L$ locus in the various mutant strains and served as a measure of residual $\mathrm{E}$ activity in the mutant strains. The results of this analysis, presented in Figure 2, confirmed our conclusions obtained by quantitative mating assays.

The only anomalous observation in these studies was that strain GJY3, which carries a deletion mutation encompassing that in DMY116, appeared to exhibit a lower level of $H M L$ expression than did strain DMY116. This result was obtained with the quantitative mating assays described above and the $\alpha$-factor confrontation assay described below, as well as with the RNase protection assays. We can only surmise that the particular context of this mutation somehow mitigates loss of the RAPl-binding site.

\section{Silencer activity does not correlate with replication activity}

Evidence accumulated previously has prompted speculation that silencer function and autonomous replication potential are functionally interrelated. All three silencer regions currently identified encompass a site for autonomous replication (Abraham et al. 1984; Feldman et al. 1984). In addition, Miller and Nasmyth (1984) showed that establishment of repression of a silent cassette can only occur if the cell passes through $\mathrm{S}$ phase. Therefore, we were interested in using our mutations to assess whether ARS function and $H M L E$ silencer activity are inextricably connected.

The deletion/substitution mutations described above allowed us to identify those regions of $\mathrm{E}$ that are neces-

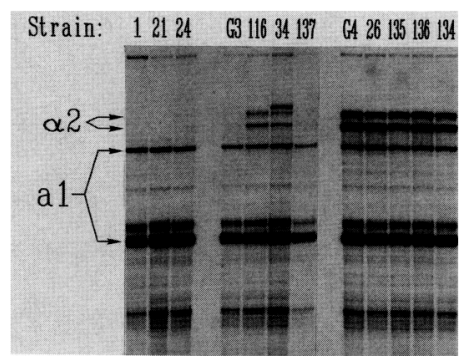

Figure 2. $H M L$-specific mRNA in strains carrying various HML E mutations. Total RNA was isolated from the designated yeast strains, and $50-\mu \mathrm{g}$ samples were hybridized with a mixture of $5 \times 10^{5} \mathrm{cpm}$ of $\alpha 2$-specific probe and $5 \times 10^{5} \mathrm{cpm}$ of al-specific probe $\left(1 \times 10^{7} \mathrm{cpm} / \mu \mathrm{g}\right)$. After hybridization and digestion with RNase $A$ and $T 1$, samples were fractionated on a $6 \%$ polyacrylamide $/ 8 \mathrm{M}$ urea gel. A section of the autoradiograph of the gel is shown, on which is indicated the position of migration of RNA fragments protected by $\alpha 2$ mRNA and those protected by a1 mRNA. The upper al fragment most likely corresponds to unspliced al mRNA; the lower al fragment corresponds to mature al mRNA. Numbers above the lanes refer to DMY or GJY (G3 and G4) strain designations listed in Table 1. The HML E site configuration in each strain is diagramed in Fig. 1. The species migrating slightly slower than the larger $\alpha 2$-specific RNA in the sample from strain DMY34 is an artifact that is not present in other equivalent assays of the same preparation of RNA. 
sary for silencer activity. To correlate this information with the replication potential of the various $\mathrm{E}$ alleles, we also examined the residual ARS activity of a fragment encompassing the $\mathrm{E}$ domain for each of the mutations. This fragment from each deletion/substitution was cloned into the integrating vector YIp19, and the ARS activity of the resultant plasmids was determined by assessing efficiency of transformation of yeast. The results of this analysis are presented in Table 1 . All of the mutations that encroach on the ARS consensus element both abolish ARS activity and severely diminish silencer function. However, several mutations clearly eliminate ARS activity without seriously affecting silencer function. Thus, at least at $H M L$, silencer function is more dependent on the integrity of the ARS consensus element than on replication potential per se. This suggests that ARS elements may participate in silencer function in some capacity other than their ability to promote initiation of DNA replication.

\section{Partial expression of HML yields two distinct cell types}

We find that mutations of $H M L \mathrm{E}$, like mutations in SIR1, yield cultures comprised of two distinct cell types. This conclusion was reached by using an $\alpha$-factor confrontation assay similar to that employed by Pillus and Rine (1989). Individual $H M L \alpha M A T$ a cells were micromanipulated into the presence of the mating pheromone, $\alpha$-factor. Cells that are derepressed at $H M L$ coexpress a-mating information from $M A T$ and $\alpha$-mating information from $H M L$. Such cells are phenotypically $\mathbf{a} / \alpha$ and

Table 1. Relation between replication potential and silencer activity

\begin{tabular}{|c|c|c|c|c|c|c|}
\hline \multirow{2}{*}{\multicolumn{3}{|c|}{$\begin{array}{c}\text { E site } \\
\text { configuration }\end{array}$}} & \multicolumn{2}{|c|}{ Replication } & \multirow{2}{*}{\multicolumn{2}{|c|}{ Repression $^{a}$}} \\
\hline & & & \multirow[b]{2}{*}{ deletion $^{\mathrm{b}}$} & \multirow{2}{*}{$\begin{array}{l}\text { ARS } \\
\text { activity }^{c}\end{array}$} & & \\
\hline $\mathrm{E}$ & A & $\mathrm{D}$ & & & strain & activity \\
\hline+ & + & + & 0 & + & DMY1 & ++ \\
\hline+ & + & + & $70-80$ & + & DMY36 & ++ \\
\hline+ & + & + & $80-90$ & + & DMY21 & ++ \\
\hline - & + & + & $90-95$ & + & DMY116 & $+1-$ \\
\hline- & - & + & $79-113$ & - & DMY26 & - \\
\hline+ & - & + & $107-119$ & - & DMY34 & $+1-$ \\
\hline+ & + & $1+1$ & $123-131$ & - & DMY24 & + \\
\hline- & - & - & $90-216$ & - & DMY136 & - \\
\hline+ & - & - & $107-216$ & - & DMY134 & - \\
\hline+ & + & - & $123-216$ & - & DMY137 & + \\
\hline
\end{tabular}

${ }^{a}$ Repression refers to the ability of an E site carrying the indicated deletion mutation to repress expression of $H M L \alpha$ in an $\mathrm{I}^{-}$ background. The strain in which the deletion's effect on repression was determined is listed. The notations represent a qualitative summary of the data in Figs. 1 and 2 and Table 2.

bPlasmids used in the ARS assays were the same as those used for integration of mutant alleles of $\mathrm{E}$ into the chromosome to yield the strains listed on the right.

cARS activity was determined as described in Materials and methods, using strain DMY1 as recipient for transformation.
Table 2. Proportion of $\alpha$-factor-sensitive cells in cultures of strains with mutations in HML $E$

\begin{tabular}{lccccl}
\hline \multicolumn{7}{c}{ Genotype $^{\mathrm{a}}$} & & & $\begin{array}{l}\text { Percent } \\
\text { sensitive }^{b}\end{array}$ \\
\hline strain & E & A & D & Sir & \\
\hline DMY1 & + & + & + & + & $100(120 / 120)$ \\
DMY18 & + & + & + & + & $100(85 / 85)$ \\
DMY21 & + & + & + & + & $100(90 / 90)$ \\
DMY116 & - & + & + & + & $42(138 / 326)$ \\
GY3 & - & + & + & + & $97(63 / 65)$ \\
DMY34 & + & - & + & + & $78(198 / 254)$ \\
DMY137 & + & + & - & + & $90(256 / 283)$ \\
DMY24 & + & + & - & + & $98(106 / 108)$ \\
GYY4 & - & - & + & + & $<1(0 / 107)$ \\
DMY2 & + & + & + & - & $<1(0 / 85)$ \\
\hline
\end{tabular}

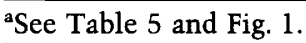

${ }^{\mathrm{b}}$ The percent $\alpha$-factor-sensitive cells in cultures of the indicated strains was determined as described in Materials and methods. The values given for strains DMY116, DMY34, and DMY137 are summed from five separate determinations on five separate cultures for each strain. The measured percentage of sensitive cells in the different cultures of strain DMY116 ranged from $24 \%$ to $55 \%$; for cultures of strain DMY34, the values ranged from $51 \%$ to $95 \%$; and for cultures of strain DMY137, the values ranged from $84 \%$ to $94 \%$.

unresponsive to a-factor (Strathern et al. 1981). Cells that are repressed for $H M L$ expression are phenotypically a cells and are, accordingly, sensitive to $\alpha$-factor. This sensitivity manifests as cell cycle arrest and, upon longer exposure, morphological alterations to yield cells with enlarged, elongated shapes called "shmoos" (Sprague et al. 1983; Cross et al. 1987). Thus, cells that show normal growth and cell division in the presence of $\alpha$-factor are derepressed for $H M L$, whereas those that undergo cell cycle arrest and shmoo formation are repressed for the locus.

Results of the confrontation assay performed with a number of strains are presented in Table 2 . As expected, the parental strains (DMY1 and DMY18), which are fully repressed for $H M L$ expression, yield only $\alpha$-factorsensitive cells, whereas strain DMY2, which is fully derepressed for $H M L$ expression by virtue of inactivation of sir3, yields only resistant cells. In contrast, strains that exhibited partial expression of $H M L$ yield a mixture of sensitive and resistant cells. In addition, the fraction of $\alpha$-factor-resistant cells in the culture of a particular strain is roughly proportional to the relative level of expression of $H M L$, averaged over the entire cell population. Thus, the $\alpha$-factor confrontation assay provides a third metric confirming the assignment and relative contributions of the three domains within E. To reflect the partial penetrance of the E alleles in strains DMY116, DMY34, and DMY137, we refer to them as $\mathrm{E}^{\mathrm{P}}$ mutations.

\section{The transcription state of HML $E^{p}$ loci shows epigenetic inheritance}

To examine the frequency with which $\alpha$-factor-resistant cells in cultures of strains DMY116, DMY34, and 
DMY137 gave rise to sensitive cells, we performed pedigree analyses on isolated cells. Individual, resistant cells were allowed to grow in the presence of $\alpha$-factor. As cells divided, the mother and daughter cells were separated by micromanipulation, and the location and identity of each were noted. This process was continued for four to six generations. If a newly emerged cell remained derepressed for $H M L$ expression, it would continue to divide. If, on the other hand, a newly emerged cell had diminished $H M L$ expression, it would cease to divide and become a shmoo. Thus, at each cell division, the expression state of the $H M L$ locus in the new mother and daughter cell could be assessed. These results are summarized in Table 3.

For all three $H M L \mathrm{E}^{\mathrm{p}}$ strains examined, an $\alpha$-factorresistant cell most often gave rise to two cells that were also $\alpha$-factor resistant. This tendency for persistence of $\alpha$-factor resistance over several generations could be quantitated as the probability that a newly emerged cell from a resistant parent would be sensitive to a-factor. For strains DMY116 and DMY34 this value was $\sim 0.08$, even though $40-50 \%$ of the cells in the population as a whole were sensitive to the pheromone. Similarly, the probability that a sensitive cell would emerge from a resistant parent for strain DMY137 was 0.2, even though $>90 \%$ of the cells in the population were sensitive. A similar persistence of the repressed state of $H M L$ could also be ob- served with these strains, although for technical reasons fewer cells were examined.

\section{Low-level expression of $\alpha 2$ yields an HML $E^{p}$} phenotype without epigenetic inheritance

To determine whether the phenotype caused by $H M L \mathrm{E}^{p}$ mutations results simply from low-level, constitutive expression of $\alpha$ mating-type information, we constructed strains in which expression of $H M L \alpha$ mating information could be regulated by a mechanism distinct from $S I R$-mediated silencing. In a MATa background, $H M L \alpha 2$ expression is solely responsible for sterility and $\alpha$-factor resistance, $H M L \alpha 1$ does not contribute to this a/ $\alpha$ phenotype. Accordingly, we constructed plasmid pAR89, in which the $H M L a 2$-coding region is fused to the galactose-inducible GAL10 promoter and integrated it into the genome of strain DMY1 to yield two independent transformants, GJY28 and GJY29. As expected, strains GJY28 and GJY29 mate as a strains when grown on glucose and are sterile when grown on galactose.

To achieve low-level, continuous $\alpha 2$ expression, we grew strains GJY28 and GJY29 on media containing 2\% glucose plus $2 \%$ galactose. During exponential growth, this condition yielded relatively constant expression of $\alpha 2$ mRNA at a level $\sim 20$-fold less than that obtained by growth on $2 \%$ galactose and from 2- to 20 -fold higher

Table 3. Frequency of appearance of $\alpha$-factor-sensitive cells in pedigrees of $\alpha$-factor-resistant cells

\begin{tabular}{|c|c|c|c|c|c|c|c|c|c|}
\hline \multirow[b]{2}{*}{ Strain } & \multirow[b]{2}{*}{ Experiment $^{a}$} & \multirow{2}{*}{$\begin{array}{l}\text { Relative } \\
\text { expression }^{\mathrm{b}}\end{array}$} & \multirow{2}{*}{$\begin{array}{c}\text { Sensitivity } \\
(\%)^{c}\end{array}$} & \multirow[b]{2}{*}{ Pedigrees } & \multirow[b]{2}{*}{ Cell divisions ${ }^{d}$} & \multicolumn{3}{|c|}{$\begin{array}{c}\text { Cell divisions } \\
\text { yielding }\end{array}$} & \multirow[b]{2}{*}{ Probability $^{f}$} \\
\hline & & & & & & $0 \mathrm{SC}$ & $1 \mathrm{SC}$ & $2 \mathrm{SC}$ & \\
\hline \multicolumn{10}{|c|}{ A. HML $E^{p}$ strains } \\
\hline \multirow[t]{2}{*}{ DMY116 } & 1 & 0.30 & 40 & 21 & 257 & 222 & 11 & 17 & 0.087 \\
\hline & 2 & $\mathrm{ND}^{7}$ & 55 & 20 & 227 & 205 & 8 & 14 & 0.079 \\
\hline DMY34 & 1 & 0.25 & 51 & 27 & 416 & 382 & 12 & 22 & 0.067 \\
\hline \multirow[t]{2}{*}{ DMY137 } & 1 & 0.1 & 93 & 3 & 39 & 31 & 3 & 5 & 0.17 \\
\hline & 2 & $\mathrm{ND}^{7}$ & 90 & 7 & 71 & 54 & 6 & 11 & 0.20 \\
\hline \multicolumn{10}{|c|}{ B. GAL10-MAT $\alpha 2$ strains } \\
\hline \multirow[t]{2}{*}{ GJY28 } & 1 & 10 & 0 & 31 & 180 & 180 & 0 & 0 & 0 \\
\hline & 2 & 3.2 & 16 & 35 & 107 & 61 & 13 & 33 & 0.37 \\
\hline \multirow[t]{2}{*}{ GJY29 } & 1 & 1.5 & 24 & 28 & 64 & 46 & 11 & 7 & 0.20 \\
\hline & 2 & 0.85 & 66 & 32 & 35 & 13 & 6 & 16 & 0.54 \\
\hline
\end{tabular}

${ }^{\text {a For } H M L} \mathrm{E}^{\mathrm{p}}$ strains, all experiments were performed under identical conditions, as described in Materials and methods. For GAL10-HML 2 strains, cells were pregrown in YEP $+2 \%$ galactose medium in experiment 1 and on YEP $+2 \%$ raffinose medium in experiment 2 . Cells were then assayed in both cases, as described in Materials and methods.

bLevel of $\alpha 2$ mRNA, relative to that in strain DMY2, as determined by densitometer scanning of autoradiograms of RNase protection assay gels similar to that shown in Fig. 1, performed on RNA isolated from the same culture used to perform pedigree analysis. (ND) Not determined.

${ }^{c}$ Percentage of $\alpha$-factor-sensitive cells present in the culture at the beginning of the pedigree analysis.

${ }^{d}$ Pedigrees were performed on individual cells maintained in the presence of $\alpha$-factor, as described in Materials and methods. Mother and daughter cells were separated following every cell division, and each was scored for sensitivity to a-factor. For $H M L \mathrm{E}^{\mathrm{P}}$ strains this process was continued for approximately six generations for all resistant cells within each pedigree. For GAL10-MAT 2 strains, this process was continued for approximately three to four generations. Value represents the number of times, among all the pedigrees in the experiment, that mother and daughter cells were separated and scored for sensitivity.

evvery cell division monitored in the pedigrees was scored as yielding no sensitive cells $(0 \mathrm{SC})$, one sensitive cell and one resistant cell (1 SC), or two sensitive cells $(2 \mathrm{SC})$.

${ }^{\mathrm{f}}$ The probability that a progeny of an $\alpha$-factor-resistant cell would be sensitive to $\alpha$-factor, calculated as $[2 \times$ (no. of divisions yielding $2 \mathrm{SC})+1 \times$ (no. of divisions yielding $1 \mathrm{SC}) /(2 \times$ (total number of cell divisions $)]$ 
than that seen in strains carrying an $H M L \mathrm{E}^{\mathrm{p}}$ mutation (Table 3B, and data not shown). Strain GJY28 consistently expressed levels of $\alpha 2$ mRNA fourfold lower than did strain GJY29. Similarly, pregrowth of the strains on raffinose (see Materials and methods) consistently yielded steady-state levels of $\alpha 2$ mRNA two- to threefold less than that obtained from cells pregrown on galactose (Table 3B). The pattern of expression for these strains and growth conditions was quite reproducible; different cultures of the same strain grown under identical conditions gave $\alpha 2$ mRNA levels that varied by less than a factor of two. Although we do not fully understand the reasons for these slight variations, their existence gave us a set of cultures with a spectrum of constant levels of $\alpha 2$ mRNA varying over a 10 -fold range. Although $\alpha 2$ mRNA levels from the $G A L 10-H M L \alpha 2$ strains are generally higher than that from $H M L \mathrm{E}^{\mathrm{p}}$ strains, the 5 -untranslated region of $\alpha 2$ mRNA derived from the GAL10-HML $\alpha 2$ allele is not the same as that of $\alpha 2$ mRNA derived from $H M L \alpha 2$. Accordingly, while relative mRNA levels should accurately mirror the relative $\alpha 2$ activity among the $H M L \mathrm{E}^{\mathrm{p}}$ strains or among GAL10-HML $\alpha 2$ strains, the level of $\alpha 2$ protein for a given level of $\alpha 2$ mRNA in GAL10-HML 2 strains is likely different, and probably less, than that in $H M L \mathrm{E}^{\mathrm{p}}$ strains.

To examine the effect of low-level $\alpha 2$ expression on the mating behavior of individual cells, strains GJY2 8 and GJY29 were grown in liquid cultures containing $2 \%$ glucose and $2 \%$ galactose, and individual cells were micromanipulated on plates of the same medium to sites adjacent to discs containing synthetic $\alpha$-factor. Individual cells were scored for sensitivity or resistance to $\alpha$-factor. In addition, we followed the progeny of resistant cells for three to four generations to determine the frequency of appearance of sensitive cells. As is the case with strains containing $H M L \mathrm{E}^{\mathrm{P}}$ mutations, strains GJY28 and GJY29 grown on glucose plus galactose consisted of a mixture of $\alpha$-factor-resistant and $\alpha$-factorsensitive cells (Table 3 ). The proportion of $\alpha$-factorresistant cells correlated with the relative level of expression of $\alpha 2$ expression, as judged by RNase protection assays. However, unlike strains containing $H M L \mathrm{E}^{\mathrm{p}}$ mutations, the transcription state of an individual cell was not transmitted efficiently to its progeny. The probability of an $\alpha$-factor-resistant cell begetting an $\alpha$-factorsensitive cell was essentially equivalent to the fraction of sensitive cells in the population.

The behavior of $\alpha$-factor-sensitive cells presented a striking distinction between strains containing $H M L \mathrm{E}^{\mathrm{p}}$ mutations and those with low-level, constant expression of $\alpha 2$. As noted in Table 4, HML $\mathrm{E}^{\mathrm{p}}$ cells initially sensitive to $\alpha$-factor remained sensitive as long as they remained in the presence of $\alpha$-factor. Generally, such cells were observed for at least $18 \mathrm{hr}$, that is, the equivalent of nine generations. In contrast, the phenotype of individual sensitive GJY28 or GJY29 cells was not stable. A number of cells that were initially sensitive to $\alpha$-factor, as judged by their failure to bud and their metamorphosis to shmoos, subsequently resumed budding while in the continuous presence of $\alpha$-factor (Table 4). Resumption of budding could occur from 2 to $12 \mathrm{hr}$ after initial exposure to $\alpha$-factor. This was not due to local depletion of $\alpha$-factor or to gradual induction of $G A L 10-\alpha 2$, since at the same time on the same plate an equivalent proportion of resistant cells yielded sensitive progeny. Thus, $\alpha$-factor-sensitive GAL10- $\alpha 2$ cells were able to escape $\alpha$-factor-induced growth arrest while $\alpha$-factor-sensitive $H M L \mathrm{E}^{\mathrm{p}}$ cells were not.

\section{Discussion}

We have presented evidence in this report that the $\mathrm{E}$ silencer adjacent to $H M L$ consists of at least three distinguishable domains. Two of these domains, a RAP-1binding site and an ARS consensus sequence, correspond to elements highlighted previously by sequence comparisons among different silencers and by binding studies with proteins that recognize the $H M L$ silencer. Mutations in either of these elements yield a marked, although not absolute, diminution in silencer activity. The third element is defined by mutations that in themselves yield only a slight reduction in silencer function but that in conjunction with mutations in the ARS element eliminate activity. We have not been able to detect binding of any protein in a yeast nuclear extract to the $D$ domain, either by gel retardation or DNase protection (data not shown). Thus, we do not know whether the D domain contributes to silencer function in its capacity as a site for binding of an as yet unidentified protein or in a more subtle capacity, such as DNA structure or spacing of critical elements.

\section{The role of $A R S$ sites in silencer function}

As noted above, several observations have prompted speculation that silencer function and autonomous replication potential are functionally interrelated. In con-

Table 4. Frequency of conversion of $\alpha$-factor-sensitive cells to resistance in the continuous presence of $\alpha$-factor

\begin{tabular}{lccc}
\hline & & \multicolumn{2}{c}{ Number of shmoos that } \\
\cline { 3 - 4 } Strain & $\begin{array}{l}\text { Percent } \\
\text { sensitive }\end{array}$ & $\begin{array}{l}\text { escaped } \\
\text { arrest }\end{array}$ & $\begin{array}{l}\text { remained } \\
\text { arrested }\end{array}$ \\
\hline DMY116 & 42 & 0 & $>200$ \\
DMY34 & 78 & 0 & $>200$ \\
DMY137 & 90 & 0 & $>250$ \\
GYY28 (R) & 17 & 7 & 49 \\
GYY29 (G) & 21 & 28 & 6 \\
GYY29 (R) & 59 & 4 & 59 \\
\hline
\end{tabular}

The indicated strains were subjected to pedigree analysis as described in the footnote to Table 3 . The percentage of $\alpha$-factor-sensitive cells present in the culture at the start of the pedigree is indicated. $\alpha$-Factor-sensitive cells arising during the course of the pedigree analysis were identified by their growth arrest and morphological elongation into characteristic schmoo shapes. Shmoos were left in the presence of $\alpha$-factor and were scored after at least $12 \mathrm{hr}$ to determine whether they resumed growth, as manifested by formation of separable daughter cells, or remained arrested. 
trast, we observed that loss of ARS activity at $H M L \mathrm{E}$ does not correlate with loss of silencer function. That is, deletion/substitution mutations that alter the ARS consensus element eliminate ARS activity completely and also cause a significant impairment in silencer function. However, two other mutations adjacent to the ARS element also eliminate ARS activity completely but have only the slightest effect on silencer activity. These mutations yield a level of expression of $H M L$, as judged by RNA levels or by the proportion of $\alpha$-factor-resistant cells, 10 times lower than that induced by consensus site mutations. Thus, the effect of a mutation on silencer function does not correlate with its effect on ARS activity. This would strongly argue that the contribution of the ARS element to silencer activity is not its potential to initiate DNA replication.

The foregoing conclusion is consistent with recent results from J. Huberman and his colleagues suggesting that $H M L \mathrm{E}$ and I sites do not function as origins of replication in the chromosome. Rather, $H M L$ is replicated late in S phase, apparently from an origin located a substantial distance internal in the chromosome (J. Huberman, pers. comm.). Thus, the results from Huberman's lab also suggest that ARS elements contribute to silencer function in some capacity other than initiating DNA replication.

If the ARS element does not contribute to silencer activity by virtue of its replication potential, what role might it be playing? S. Gasser and her colleagues have shown that yeast nuclear extracts contain a DNA-binding protein that recognizes the ARS consensus element (S. Gasser, pers. comm.) Thus, a reasonable possibility is that like the RAP1 and ABFl sites, ARS elements simply provide yet another site for binding a specific nuclear protein. This hypothesis is not inconsistent with observations by Miller and Nasmyth (1980), who noted that progression through the cell cycle was necessary for reestablishing SIR repression. While establishment of repression may require replication, such replication does not necessarily have to initiate at the silencers themselves.

By integrating the available information on the structures of the known mating-type silencers, we can begin to define what constitutes a silencer. One reasonable hypothesis is that the various proteins bound to their cognate sites within the silencer domain, along with the histone octomers, present a structure recognized by the $S I R$ proteins. The particular proteins bound to the silencer would be less significant than the actual proteinaceous surface presented by the bound proteins. The SIR proteins, tethered to these binding proteins for simply rendered at high concentration through interaction with the binding proteins|, would then act in some yet unspecified way to restrict access of RNA polymerases to the region around the silencer.

\section{Are silencers two-state switches?}

We have noted that mutations in any of the three E site elements yield partial expression of the mating-type genes resident at $H M L$, as measured by procedures that evaluate expression on a population-wide basis. By examining phenotypic expression of individual cells in cultures of the mutant strains, we found that such strains yield a mixture of two cells types. One class exhibited a phenotype consistent with the $H M L$ locus being repressed, and the other class exhibited a phenotype consistent with the locus being derepressed. In addition, the proportion of phenotypically derepressed cells is equivalent to the relative level of $H M L$-specific mRNA in the strain.

The presence of a mixture of $\alpha$-factor-sensitive and -resistant cells in a culture of any of the $\mathrm{E}^{\mathrm{p}}$ strains argues that the level of expression of $H M L$ is not identical in each cell in a culture. If it were, then all of the cells would either be resistant or sensitive. However, the presence of both cell types can be explained by either of two models. On the one hand, expression of $H M L$ could be limited to only two distinct states, either completely repressed or fully derepressed. In any one cell cycle the locus would be either on or off and the cell would be either resistant or sensitive to $\alpha$-factor, accordingly. On the other hand, the level of expression of $H M L$ could show a broad distribution from cell to cell in the culture. All of the cells with an $H M L$ expression level above a certain threshold value would assume an $a / \alpha$ phenotype and exhibit resistance to $\alpha$-factor, and those with levels below that value would be sensitive.

Two observations argue against variable $H M L$ expression levels in cells with $\mathrm{E}^{\mathrm{P}}$ mutations and in favor of a two-state model for $H M L$ transcription. First, all cells that are sensitive to $\alpha$-factor remain so as long as they are kept in the presence of the pheromone. In the experiments listed in Table 4, cells were observed over a period of $12 \mathrm{hr}$ (the equivalent of six generations), and in no case did a cell initially sensitive to $\alpha$-factor begin budding while being maintained in the presence of $\alpha$-factor. This behavior is quite distinct from that of cells in which $\alpha 2$ expression is at a low, constant level. In this case, we do observe acquisition of $\alpha$-factor resistance by cells that are initially sensitive to the pheromone, suggesting that in these cells fluctuation in intracellular $\alpha 2$ mRNA is sufficient for transition across the threshold level. In contrast, the level of $H M L$ expression in strains with $H M L \mathrm{E}^{\mathrm{p}}$ mutations does not show sufficient fluctuation over time to allow phenotypic conversion from sensitivity to resistance.

A second observation supporting a two-state model of $H M L$ expression emerges from our pedigree analysis. If cells could assume a variety of $H M L$ transcription levels, we might predict that at each generation cells would tend to recapitulate the same distribution of expression levels. Although this prediction is fulfilled by strains exhibiting low-level, constitutive expression of $H M L \alpha 2$, sensitivity or resistance to $\alpha$-factor in $H M L \mathrm{E}^{\mathrm{p}}$ strains tends to be inherited. Thus, the probability that a newly emerged cell will be derepressed for $H M L$ expression is a function of its parentage rather than of the relative level of expression of the locus as measured on a populationwide basis. These observations are consistent with an all 
or none mode of repression of expression of $H M L \mathrm{E}^{\mathrm{p}}$ strains.

\section{Epigenetic inheritance of the transcription state of HML}

The repression state of $H M L$ in strains containing $\mathrm{E}^{\mathrm{p}}$ mutations tends to persist over many generations. For instance, although approximately half of the cells in a culture of strain DMY116 are phenotypically repressed for $H M L$, a cell derepressed for the locus exhibits a probability $>90 \%$ of siring two derepressed cells. Similarly, $>80 \%$ of the offspring of DMY137 cells derepressed for $H M L$ are also derepressed, even though only $10 \%$ of the cells in a culture of the strain are derepressed. These results are similar to those found for $\operatorname{sir} 1$ strains by Pillus and Rine (1989), although the rate of conversion from cells derepressed for $H M L$ to those repressed was significantly slower in $\operatorname{sir} 1$ strains than the rate observed for strains with $H M L \mathrm{E}^{\mathrm{p}}$ mutations.

Epigenetic inheritance of the $H M L$ repression state is not readily explained by the mechanisms invoked previously to account for cases of epigenetic inheritance in bacterial cells, nor is DNA methylation likely to be responsible. However, the pattern of repression of $H M L$ could be explained by a variety of models. For instance, genetic imprinting of the locus could be the result of cooperative binding of specific proteins to the silencer region. The subset of proteins remaining with each of the two strands following replication would serve to seed formation of a full repression complex. Alternatively, genetic imprinting of the silent cassettes could occur at the level of chromatin modification, perhaps in the degree of acetylation of the lysine residues in the amino-terminal region of histones. This model would require (1) that modification of histones in chromatin yields repression of the silent cassette and (2) that the complex responsible for chromatin modification across the silent cassette has a significantly higher affinity for modified chromatin than for normal chromatin.

Regardless of the specific mechanism, epigenetic inheritance appears to be an intrinsic characteristic of the repression of the silent cassettes. To date, a number of different mutations reveal the underlying epigenetic nature of SIR repression of the silent loci. These include the three alleles of $H M L \mathrm{E}$ described in this work and inactivating alleles of sir1 (Pillus and Rine 1989). It is unlikely that these different mutations all impose an epigenetic component to a system that is otherwise not heritable. Rather, it is more likely that these various mutations simply reduce the efficiency of the process from $100 \%$ to some lower value, which is experimentally accessible. The value of this genetic imprinting to the cell is that establishment of repression at each generation is not left to random association of repressor proteins with DNA. Rather, the repression complex not only prevents expression of the silent loci in the current generation but also acts as template for the repression complexes in the subsequent generations.

\section{Materials and methods}

Plasmid constructions

Deletion/substitution mutations of the HML E domain were created by the scanning linker mutagenesis protocol of McKnight and Kingsbury (1982). Two plasmids were constructed, each carrying a fragment from HML. The two fragments overlapped only across the 150 -bp E silencer. A set of unidirectional deletions were obtained in each of these plasmids, entering the $\mathrm{E}$ domain from opposite directions. Deletions removing sequences from the telomere side of the site were constructed in plasmid 637 (Feldman et al. 1984) by digesting it with $\mathrm{BamHI}$ and then treating the digested DNA with exonuclease III and S1 nuclease. Deletions removing sequences from the centromere proximal side of $\mathrm{E}$ were constructed in plasmid pDM52, by BAL-31 treatment of EcoRI-digested DNA. Plasmid pDM52 consists of a 1.7-Kb EcoRI-BamHI yeast genomic fragment, originating from the telomere proximal side of $H M L$ and encompassing the $\mathrm{E}$ site, cloned into plasmid pUCl8 (see Fig. 1). For both sets of deletion plasmids, a BglII octanucleotide linker (CAGATCTG) was inserted at the site of each deletion.

To create deletion and substitution mutations of $\mathrm{E}$, a fragment from one deletion set was matched with a corresponding fragment from the second deletion set. Matched deletions were joined by ligating the appropriate BglII-Sall fragment from a pDM52 deletion derivative into BgIII-SalI-digested DNA from the selected derivative of plasmid 637 . The net deletion size and the exact deletion end points were determined by sequencing across the BgIII linker in each reconstructed plasmid, using the method of Sanger et al. (1977), and priming denatured, doublestranded plasmid DNA with an oligonucleotide corresponding to position 3-20 or 153-137 of the E region [numbering system of Feldman et al. (1984)]. To facilitate subsequent strain construction, the BamHI-SpeI fragment spanning the mutant $\mathrm{E}$ site in each reconstructed plasmid was subcloned into the BamHIXbaI-digested YIp19 DNA. Plasmid YIp19 consists of the HindIII fragment spanning URA3, cloned into the HindIII site of plasmid pUC19. YIp19 carrying the wild-type BamHI-SpeI fragment is designated plasmid pDM26.

Plasmid pAR89 was constructed by cloning the $2.4-\mathrm{kb}$ XhoIHindIII fragment from plasmid pS353 into XhoI-HindIIIdigested YIp51 DNA. Plasmid pS353 carries the MAT $\alpha$ deletion allele L92, in which an XhoI linker is inserted 5' to the MATa2 transcription start site (Siliciano and Tatchell 1984). Plasmid YIp5l is an $A R S^{-}$derivative of YEp51 (Broach et al. 1983a), created by deleting the 1060-bp NsiI fragment spanning FRT and the 2-micron circle origin of replication.

\section{Strain construction}

Yeast strains used in this study are isogenic derivatives of the parental strain DMY1 and are listed in Table 5. Genetic manipulations were designed to generate strains that contained deletions of differing regions of the E site of $H M L$ but that were free of exogenous DNA. The strategy used was a two-step gene replacement procedure essentially as described by Scherer and Davis (1979), as modified by Boeke et al. (1987). Construction of the recipient strain DMY19 has been described previously (Mahoney and Broach 1989). This strain carries a small deletion covering the $H M L$ I silencer and a substitution of the SUP4 ochre suppressor for the $H M L \mathrm{E}$ silencer. This strain was transformed by the lithium acetate procedure of Ito et al. (1983), using XhoI-digested plasmid DNA from each of the YIp19-HML E allele constructs described in the preceding section. This 
Table 5. Yeast strains used in this study

\begin{tabular}{|c|c|}
\hline Strain & Genotype \\
\hline DMY1 & $\begin{array}{l}\text { HMLa MATa HMRa ura3-52 leu2-3,112 ade2-1 } \\
\text { lys1-1 his5-2 can1-100 }\end{array}$ \\
\hline DMY2 & DMY1; sir3 : : LEU2 \\
\hline DMY19 & DMY1; $H M L \alpha$ E $\Delta 79-113:: S U P 4-o$ I $\Delta 242$ \\
\hline DMY21 & DMY1; $H M L \alpha$ E $\Delta 80-90 \mathrm{I} \Delta 242$ \\
\hline DMY24 & $\mathrm{DMY} 1 ; H M L \alpha \mathrm{E} \Delta 123-131 \mathrm{I} \Delta 242$ \\
\hline DMY26 & $\mathrm{DMY}{ }_{i} H M L \alpha \mathrm{E} \Delta 79-113 \mathrm{I} \Delta 242$ \\
\hline DMY34 & DMY1; HML $\alpha$ E $\Delta 107-119$ I $\Delta 242$ \\
\hline DMY35 & $\mathrm{DMY} 1 ; H M L \alpha \mathrm{E} \Delta 59-76 \mathrm{I} \Delta 242$ \\
\hline DMY36 & $\mathrm{DMY} 1 ; H M L \alpha \mathrm{E} \Delta 70-80 \mathrm{I} \Delta 242$ \\
\hline DMY116 & DMY1; $H M L \alpha$ E $\Delta 90-95$ I $\Delta 242$ \\
\hline DMY134 & DMY1; $H M L \alpha$ E $\Delta 107-216$ I $\Delta 242$ \\
\hline DMY136 & $\mathrm{DMY} 1 ; H M L \alpha \mathrm{E} \Delta 90-216 \mathrm{I} \Delta 242$ \\
\hline DMY137 & $\mathrm{DMY} 1 ; H M L \alpha \mathrm{E} \Delta 123-216 \mathrm{I} \Delta 242$ \\
\hline GIY3 & $\mathrm{DMY} 1 ; H M L \alpha \mathrm{E} \Delta(-100)-95 \mathrm{I} \Delta 242$ \\
\hline GJY4 & $\mathrm{DMY} 1 ; H M L \alpha \mathrm{E} \Delta(-100)-119 \mathrm{I} \Delta 242$ \\
\hline GJY6 & DMY1; $H M L \alpha \mathrm{E} \Delta(-100)-90 \mathrm{I} \Delta 242$ \\
\hline GJY28 & DMY1; leu2::LEU2-GAL10-MATa2 \\
\hline GIY29 & DMY1; leu2::LEU2-GAL10-MAT $\alpha 2$ \\
\hline DC14 & MATa his1 \\
\hline DC17 & $M A T \alpha$ his1 \\
\hline
\end{tabular}

yielded circular integration of the entire plasmid into the $H M L$ locus. Derivatives of the transformants that had excised the integrated plasmid were then selected by growth on 5-fluoroorotic acid (5-FOA). Those clones that had excised the integrated plasmid and left the new $\mathrm{E}$ allele in the chromosome were identified by the concurrent acquisition of 5-FOA resistance and loss of SUP4 suppressor activity. The configuration of $H M L$ in every yeast strain used was confirmed by Southern blot analysis.

Strains GJY28 and GJY29 were constructed by transforming strain DMY1 to leucine prototrophy with BstEII-digested pAR89 DNA.

\section{Quantitative matings}

Quantitative matings were performed essentially as described by Dutcher and Hartwell (1982), as modified by Mahoney and Broach (1989).

\section{RNA analysis}

Total yeast RNA was prepared essentially as described by Carlson and Botstein (1982), as modified by Mahoney and Broach (1989).

\footnotetext{
ARS assays

$H M L \mathrm{E}$ site deletion mutations were tested for ARS activity by transforming strain DMY1 with YIp19 carrying a BamHI-SpeI fragment spanning the mutant allele. Plasmid pDM26, which carries the wild-type $H M L$ E site, generally yielded $>1000 \mathrm{Ura}^{-}$ transformants per milligram of DNA. Plasmids that gave similar numbers of transformants were scored as replication competent, whereas those that yielded less than five colonies per microgram of DNA were scored as replication deficient.
}

$\alpha$-Factor confrontation assay

A thick streak of DC17 cells was applied to a YEPD (1\% yeast extract, $2 \%$ bactopeptone, $2 \%$ glucose) plate and incubated at $30^{\circ} \mathrm{C}$ for 2 days. A sample of an exponential culture of a test strain was then deposited on the plate several centimeters away from the streak of DC17 cells. Approximately 50-100 cells from the culture were manipulated en masse to a site adjacent to the streak of DC17 cells, and individual cells were deposited $\sim 0.2$ $\mathrm{mm}$ from the boundary of the DC17 cells. The presence and size of buds on each cell were noted. The plate was incubated for 6-8 hr at $30^{\circ} \mathrm{C}$, and the cells were re-examined microscopically. Those cells that had failed to divide and had become anisotropically elongated were scored as $\alpha$-factor sensitive. In addition, those cells that were initially budded and yielded only two cells, both of which were anisotropically elongated, were also scored as $\alpha$-factor resistant. Cells that had divided more than once were scored as resistant to $\alpha$-factor. The rare cell that neither divided nor elongated was presumed to be dead. These appeared in all cultures at $<1 \%$.

\section{Pedigrees performed in the presence of $\alpha$-factor}

Individual test cells were manipulated adjacent to a streak of $\mathrm{DC} 17$ cells as described above. At 1 - to $1 \frac{1 / 2}{2}$ hr intervals, cells were examined, and those that had completed cell division were separated and the location and bud sizes were noted. This process was continued until the initial cell had undergone five to six divisions. At any point, a cell that failed to undergo division and became elongated instead was scored as $\alpha$-factor sensitive. At the end of the experiment, the plate was incubated for an additional $8 \mathrm{hr}$ so that newly emerged cells could be scored as sensitive or resistant as described above.

For strains GJY28 and GJY29, cells were pregrown either in YEP ( $2 \%$ yeast extract, $1 \%$ bactopeptone) plus $2 \%$ galactose or in YEP plus $2 \%$ raffinose and then inoculated to $10^{4}$ cells $/ \mathrm{ml}$ in $\mathrm{YEP} / 2 \%$ galactose $/ 2 \%$ glucose. After $12 \mathrm{hr}$ of growth at $30^{\circ} \mathrm{C}$, cells were removed for $\alpha$-factor confrontation assays and pedigree analyses, which were performed on YEP plates containing $2 \%$ glucose plus $2 \%$ galactose. Individual cells were micromanipulated to within $0.3 \mathrm{~mm}$ of a disc saturated with $200 \mathrm{ng}$ of synthetic $\alpha$-factor (Sigma), and observed and treated as described above. For each experiment, cells from strains DMY1, DMY2, and DMY116 were also positioned next to the saturated disc and scored for the proportion of sensitive cells. In all cases, these control strains gave the same results as those obtained by the protocol described above.

\section{Acknowledgments}

D.J.M was supported by a predoctoral training grant from the National Cancer Institute, and A.B.R. by a predoctoral fellowship from the Natural Sciences and Engineering Research Council of Canada. This work was supported by a grant from the American Cancer Society to J.R.B.

The publication costs of this article were defrayed in part by payment of page charges. This article must therefore be hereby marked "advertisement" in accordance with 18 USC section 1734 solely to indicate this fact.

\section{References}

Abraham, J., J. Feldman, K.A. Nasmyth, J.N. Strathern, A.J.S. Klar, J.R. Broach, and J.B. Hicks. 1983. Sites required for position-effect regulation of mating-type information in yeast. Cold Spring Harbor Symp. Quant. Biol. 47: 989-998. 
Abraham, J., K.A. Nasmyth, J.N. Strathern, A.J.S. Klar, and J.B. Hicks. 1984. Regulation of mating-type information in yeast: Negative control requiring sequences both $5^{\prime}$ and $3^{\prime}$ to the regulated region. J. Mol. Biol. 176: 307-331.

Astell, C.R., L. Ahlstrom-Jonasson, M. Smith, K. Tatchell, K.A. Nasmyth, and B.D. Hall. 1981. The sequence of the DNAs coding for the mating-type loci of Saccharomyces cerevisiae. Cell 27: 15-23.

Boeke, J.D., J. Trueheart, G. Natsoulis, and G.R. Fink. 1987. 5-Fluoroorotic acid as a selective agent in yeast molecular genetics. Methods Enzymol. 154E: 164-175.

Brand, A.H., L. Breeden, J. Abraham, R. Sternglanz, and K. Nasmyth. 1985. Characterization of a silencer in yeast: A DNA sequence with properties opposite to those of a transcriptional enhancer. Cell 41: 41-48.

Brand, A.H., G. Micklem, and K. Nasmyth. 1987. A yeast silencer contains sequences that can promote autonomous plasmid replication and transcriptional activation. Cell 51: 709-719.

Broach, J.R., Y.Y. Li, L.C.C. Wu, and M. Jayaram. 1983a. Vectors for high-level, inducible expression of cloned genes in yeast. In Experimental manipulation of gene expression (ed. M. Inouye), pp. 83-117. Academic Press, New York.

Broach, J.R., Y.Y. Li, J.B. Feldman, M. Jayaram, J. Abraham, K.A. Nasmyth, and J.B. Hicks. 1983b. Localization and sequence analysis of yeast origins of DNA replication. Cold Spring Harbor Symp. Quant. Biol. 47: 1165-1173.

Buchman, A.R., W.J. Kimmerly, J. Rine, and R.D. Kornberg. 1988. Two DNA-binding factors recognize specific sequences at silencers, upstream activating sequences, autonomously replicating sequences, and telomeres in Saccharomyces cerevisiae. Mol. Cell. Biol. 8: 210-225.

Carlson, M. and D. Botstein. 1982. Two differentially regulated mRNAs with different $5^{\prime}$ ends encode secreted and intracellular forms of yeast invertase. Cell 28: 145-154.

Cedar, H. 1988. DNA methylation and gene activity. Cell 53: 3-4.

Cohn, M. and K. Horibata. 1959. Inhibition by glucose of the induced synthesis of the beta-galactosidase-enzyme system of Escherichia coli. Analysis of maintenance. J. Bacteriol. 78: 601-612.

Cross, F., L.H. Hartwell, C. Jackson, and J.B. Konopka. 1987. Conjugation in Saccharomyces cerevisiae. Annu. Rev. Cell Biol. 4: 429-457.

Dranginis, A. 1986. Regulation of cell type in yeast by the mating-type locus. Trends Biochem. Sci. 11: 328-331.

Dutcher, S.K. and L. Hartwell. 1982. The role of Saccharomyces cerevisiae CDC genes in nuclear fusion. Genetics 100: 175184.

Eisen, H., P. Brachet, P. da Silva, and F. Jacob. 1970. Regulation of repressor expression in lambda. proc. Natl. Acad. Sci. 66: 855-862.

Feldman, J.B., J.B. HIcks, and J.R. Broach. 1984. Identification of the sites required for repression of a silent mating type locus in yeast. J. Mol. Biol. 178: 815-834.

Haber, J.E. 1983. Mating type genes of Saccharomyces cerevisiae. In Mobile genetic elements (ed. J. Shapiro), pp. 559-619. Academic Press, New York.

Haber, J.E. and J.P. George. 1979. A mutation that permits the expression of normally silent copies of mating-type information in Saccharomyces cerevisiae. Genetics 93: 13-35.

Herskowitz, I. 1989. A regulatory hierarchy for cell specilization in yeast. Nature 342: 749-757.

Herskowitz, I. and Y. Oshima. 1981. Control of cell type in yeast. In The molecular biology of the yeast Saccharomyces (ed. J.N. Strathern, E.W. Jones, and J.R. Broach), pp. 181-209.
Cold Spring Harbor Laboratory, Cold Spring Harbor, New York.

Hicks, J.B., J.N. Strathern, and A.J.S. Klar. 1979. Transposable mating type genes in Saccharomyces cerevisiae. Nature 282: $478-483$.

Holliday, R. 1988. The inheritance of epigenetic defects. Science 238: $163-170$.

Ito, H., Y. Fukuda, K, Murata, and A. Kimura. 1983. Transformation of intact yeast cells treated with alkali ions. $J$. Bacteriol. 153: 163-168.

Ivy, J.M., A.J.S. Klar, and J.B. Hicks. 1986. Cloning and characterization of four SIR genes of Saccharomyces cerevisiae. Mol. Cell. Biol. 6: 688-702.

Kayne, P.S., U.J. Kim, M. Han, J.R. Mullen, F. Yoshizaki, and M. Grunstein. 1988. Extremely conserved histone $\mathrm{H} 4 \mathrm{~N}$ terminus is dispensable for growth but essential for repressing the silent mating loci in yeast. Cell 55: 27-39.

Kimmerly, W., A. Buchman, R. Kornberg, and J. Rine. 1988. Roles of two DNA-binding factors in replication, segregation and transcriptional repression mediate by a yeast silencer. EMBO I. 7: 2241-2253.

Klar, A.J.S. 1980. Interconversion of yeast cell types by transposable genes. Genetics 95: 631-648.

Klar, A.J.S. and S. Fogel. 1979. Activation of mating type genes by transposition in Saccharomyces cerevisiae. Proc. Natl. Acad. Sci. 76: 4539-4543.

Klar, A.J.S., S. Fogel, and K. MacLeod. 1979. Marl-A regulator of HMa and HM(alpha) loci in Saccharomyces cerevisiae. Genetics 93: 37-50.

Klar, A.J.S., J.N. Strathern, J.R. Broach, and J.B. Hicks. 1981. Regulation of transcription in expressed and unexpressed mating type cassettes of yeast. Nature 289: 239-244.

Klar, A.J.S., J.B. Hicks, and J.N. Strathern. 1982. Directionality of yeast mating-type interconversion. Cell 28: 551-561.

Klar, A.J.S., J.N. Strathern, and J.B. Hicks. 1984. Developmental pathways in yeast. In Microbial development (ed. R. Losick and L. Shapirol, pp. 151-195. Cold Spring Harbor Laboratory, Cold Spring Harbor, New York.

Kushner, P.J., L.C. Blair, and I. Herskowitz. 1979. Control of yeast cell types by mobile genes: A test. Proc. Natl. Acad. Sci. 76: 5264-5268.

Mahoney, D.J. and J.R. Broach. 1989. The HML mating-type cassette of Saccharomyces cerevisiae is regulated by two separate but functionally equivalent silencers. Mol. Cell. Biol. 9: 4621-4630.

McKnight, S. and R. Kingsbury. 1982. Transcriptional control signals of a eukaryotic protein coding gene. Nature 217: 316-317.

Miller, A.M. and K.A. Nasmyth. 1984. Role of DNA replication in the repression of silent mating type loci in yeast. Nature 312: 247-251.

Nasmyth, K.A. 1982. Molecular genetics of yeast mating type. Annu. Rev. Genet. 16: 439-500.

Nasmyth, K.A. and K. Tatchell. 1980. The structure of transposable yeast mating type loci. Cell 19: 753-764.

Nasmyth, K.A., K. Tatchell, B.D. Hall, C.R. Astell, and M. Smith. 1981. A position effect in the control of transcription at yeast mating type loci. Nature 289: 244-250.

Pillus, L. and J. Rine. 1989. Epigenetic inheritance of transcription states in S. cerevisiae. Cell 59: 637-647.

Rine, J. and I. Herskowitz. 1987. Four genes responsible for a position effect on expression from HML and HMR in Saccharomyces cerevisiae. Genetics 116: 9-22.

Rine, J.D., J.N. Strathern, J.B. Hicks, and I. Herskowitz. 1979. A suppressor of mating-type locus mutations in Saccharomyces cerevisiae: Evidence for and identification of cryptic 
mating type loci. Genetics 93: 877-901.

Sanger, F., S. Nicklen, and A.R. Coulson. 1977. DNA sequencing with chain-terminating inhibitors. Proc. Natl. Acad. Sci. 74: 5463-5467.

Scherer, S. and R.W. Davis. 1979. Replacement of chromosome segments with altered DNA sequences constructed in vitro. Proc. Natl. Acad. Sci. 76: 4951-4955.

Schnell, R. and J. Rine. 1986. A position effect on the expression of a tRNA gene mediated by the SIR genes in Saccharomyces cerevisiae. Mol. Cell. Biol. 6: 494-501.

Shore, D. and K. Nasmyth. 1987. Purification and cloning of a DNA-binding protein from yeast that binds to both silencer and activator elements. Cell 51: 721-732.

Shore, D., D.J. Stillman, A.H. Brand, and K.A. Nasmyth. 1987. Identification of silencer binding proteins from yeast: Possible roles in SIR control and DNA replication. EMBO J. 6: $461-467$.

Siliciano, P.G. and K. Tatchell. 1984. Transcription and regulatory signals at the mating type locus in yeast. Cell 37:969978.

Sprague, G.F. Jr., L.C. Blair, and J. Thorner. 1983. Cell interactions and regulation of cell type in the yeast Saccharomyces cerevisiae. Annu. Rev. Microbiol. 37: 623-660.

Strathern, J.N., J.B. Hicks, and I. Herskowitz. 1981. Control of cell type in yeasst by the mating type locus: The (alpha)(alpha)2 hypothesis. J. Mol, Biol. 147: 357-372.

Swain, J.L., T.A. Stewart, P. Leder. 1987. Parental legacy determines methylation and expression of an autosomal transgene: A molecular mechanism for parental imprinting. Cell 50: 719-727. 


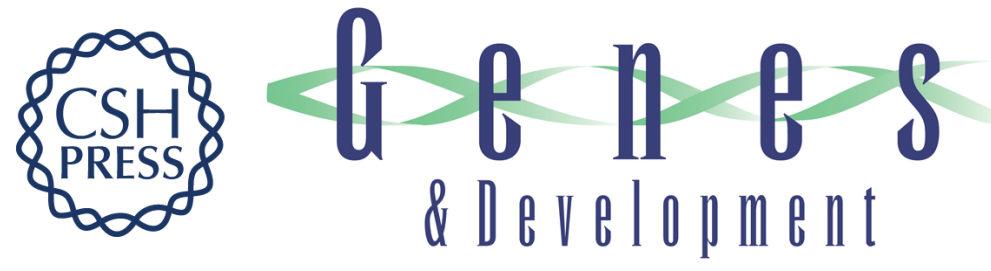

\section{Mutations in the HML E silencer of Saccharomyces cerevisiae yield metastable inheritance of transcriptional repression.}

D J Mahoney, R Marquardt, G J Shei, et al.

Genes Dev. 1991, 5:

Access the most recent version at doi:10.1101/gad.5.4.605

References This article cites 48 articles, 18 of which can be accessed free at: http://genesdev.cshlp.org/content/5/4/605.full.html\#ref-list-1

License

Email Alerting

Service

Receive free email alerts when new articles cite this article - sign up in the box at the top right corner of the article or click here.

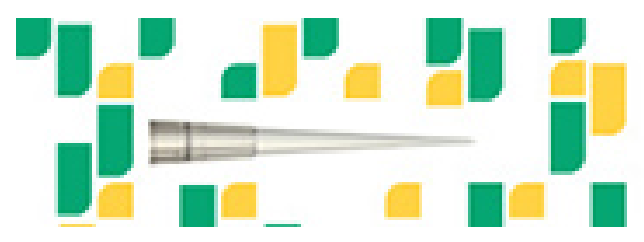

Focused on your science. 